\title{
Defects and Reform Direction of English Teaching Methods
}

\author{
Song Wang ${ }^{1,}$, Xiangfa Zeng ${ }^{2, b}$ * \\ ${ }^{1}$ Chengdu Medical College, Chengdu, Sichuan \\ $2{ }^{*}$ Corresponding Author, Chengdu Medical College, Chengdu, Sichuan \\ a wsong80@126.com, ${ }^{\mathrm{b}}$ 1362806408@qq.com \\ ${ }^{*}$ Corresponding Author
}

Keywords: defects; reform; teaching methods; specialized English

\begin{abstract}
The defects of the traditional English teaching mode are exposed day by day, so it is imperative to reform the traditional English teaching mode. In the process of college English teaching reform, there are still some teachers who hold conservative ideas and have a negative attitude towards the reform. There are a lot of defects in the teaching methods of traditional English teaching. The evaluation system of English education is unreasonable, the level of teachers needs to be improved, the aims of English teaching are not very clear, and the teaching mode is too old-fashioned. In view of the defects in traditional English teaching, this paper studies the reform of English teaching methods in order to cultivate practical English talents who serve the economy and society directly, to strengthen the teaching of specialized English, and to improve the listening ability of students. Students' interest in learning, their enthusiasm for participating in classroom learning and their autonomy of learning after class are enhanced by means of reforming English teaching methods. In order to meet the needs of practical English teaching, it is required to strengthen the cultivation of English communicative competence and the learning of specialized English knowledge and emphasize the application of basic theoretical knowledge and the cultivation of students' practical ability.
\end{abstract}

\section{Introduction}

With the development of economy, science and technology and the deepening of cultural exchange, the society needs more and more English talents, so it puts forward higher requirements for college English teaching. In accordance with the specific situation of the university and the actual situation of college English teaching, every university should actively reform the college English teaching ${ }^{[1]}$. As to the problems existing in the contemporary college English teaching, each university should actively reform the teaching of college English in the light of the actual situation of college English teaching ${ }^{[2]}$. It is very necessary for colleges and universities to actively carry out the reform of college English teaching. With the development of our country's economy, the demand for English comprehensive talents is more and more intense in the new historical period. How to cultivate English comprehensive talents in the new era has become the core topic. The reform of college English teaching is urgent to cultivate high-quality comprehensive talents. In the process of promoting the reform of college English teaching, colleges and universities must start from the fundamental source and change the traditional teaching methods ${ }^{[3]}$. It is necessary to renew English teaching mode. We should pay attention to the students' active exploration of knowledge and explore the true meaning and connotation of the knowledge they have learned. College English teaching is an important part of higher education. Although the level of teaching and scientific research has been greatly improved, there are still many problems, so it is urgent to deepen the reform of education and teaching ${ }^{[4]}$.

The reform of English teaching is an urgent need for the development of higher education as well as the development of social economy. Only by overcoming the shortcomings of traditional English teaching can English teaching have new vitality and develop in a more correct and bright direction. Only with reforms can we cultivate more innovative talents with strong practical ability 
and high comprehensive quality. This paper first analyzes the present situation and defects of English teaching and analyze the reform of college English teaching mode by combining the demand of quality teaching so as to promote the improvement of English teaching level and quality.

\section{Present situation of College English Teaching}

With the development of economy and the constant progress of society, it is imperative to design an English teaching model which accords with the characteristics of Chinese students. Many experts and scholars have put forward very good suggestions for the reform of English teaching, but those suggestions are to achieve some specific goals in some aspects for the current college English teaching. The problems in college English teaching in China are mainly reflected in the following aspects $^{[5]}$ :

\subsection{Relatively backward teaching concept}

In the process of college English teaching reform, there are still some teachers who hold conservative ideas and have a negative attitude towards the reform. In their thinking, the traditional teaching ideas have taken root and formed a fixed pattern. Scholars have conducted a survey of teachers in many schools in China and found that $90 \%$ of teachers still think they are explaining and demonstrating their language knowledge in the classroom ${ }^{[6]}$. Some teachers hold a positive attitude towards the "student-centered" and "communicative" teaching concepts, but they do not know how to apply them in the specific teaching process. The reason why these teachers retain traditional teachers' ideas and methods is not only influenced by national cultural factors, but also related to the traditional education they received from childhood. This lagged teaching concept seriously affects and restricts the improvement of college English teaching efficiency and quality ${ }^{[7]}$.

\subsection{Low teachers' level}

The teaching level of college English teachers is one of the key factors affecting the quality of college English teaching, because the teaching level of teachers directly affects the students' level of English learning. The English teaching of college is different from that of junior high school. It not only requires teachers to have solid knowledge of English language, but also requires teachers to have rich knowledge of culture, history, science and technology, business and so on. The requirement of this kind of complex social development makes college English teachers present the defects of single implementation structure and narrow knowledge, which will inevitably affect the improvement of students' English level and the improvement of college English teaching level ${ }^{[8]}$.

\subsection{Unitary English teaching method}

In the current college English teaching, most teachers still use the "arbitrary" teaching method to inculcate the language knowledge. In the practical teaching, the explanation of grammar rules, the listing of vocabulary usage and the translation of texts are regarded as the key points of classroom teaching, while the importance of language use is neglected ${ }^{[9]}$. In curriculum design, language knowledge is closely related to society, culture, science and technology, and the centered position of students in class is ignored. This kind of teaching method will restrain the students' enthusiasm of learning English and then affect the effectiveness of English teaching.

\subsection{Unreasonable evaluation system}

The main ways to test the effectiveness of college English teaching are CET-4 and CET- 6 with great influence and importance which play an important role in promoting college English teaching in China. However, with the development of society, the contents and forms of CET-4 and CET-6 designed according to the syllabus show obvious antiquities, and the advantages of CET-4 and CET-6 are also disappearing and the disadvantages of CET- 4 and CET- 6 are becoming more and more obvious. Moreover, in order to make students get high scores in CET-4 and CET-6, many teachers do not hesitate to disrupt the normal teaching rules and highlight the exam-oriented teaching. 


\section{Defects of Teaching Methods in English Education}

\subsection{Teaching objectives are not very clear and the teaching model is too old-fashioned}

The goal of higher education is to train applied talents with certain practical ability. At present, many colleges and universities in our country still follow the traditional "compressed" teaching mode, and the teaching is still stuck in the traditional teaching means of "textbook chalk blackboard recorder”. The phenomena such as ignoring the cultivation of ability, setting high and wide teaching goals, and applying the "one-size-fits-all” mode still exist in the teaching content, arrangement and requirement, which limits the cultivation of creative thinking and the potential development of college students ${ }^{[10]}$. It also neglects the cultivation of students' application ability, which is out of line with the social demands.

\subsection{Students have diverse levels of English and their overall English proficiency is uneven}

The students in colleges and universities have different levels of English competence with individualized demands. Most of them are lack of interest, motivation and even confidence in English learning with a strong sense of learning anxiety, which makes it difficult to improve the quality of English teaching.

\subsection{English teaching in higher vocational colleges lacks pertinence, timeliness and specialty characteristics}

The English teaching aim of higher education is to train "vocational skill type" and "applied type" talents for the society, but at present the English of higher education has no outstanding features of specialized English. Through the investigation, only some colleges have offered specialized English such as computer English, automobile English, accounting English and so on, and the pertinence to their major is not strong. There are many shortcomings and defects in the existing curriculum. The content and structure of the textbook cannot meet the actual needs.

\section{Reform direction of College English Teaching}

\subsection{Reform of English curriculum and teaching objectives}

Under the new talent training model, English courses of higher education should be carried out in two stages. In the first stage, "English Course" should be divided into two parts including "basic English course" and "specialized English Courses". The first stage should be completed in the first two semesters. The second stage is the improvement stage completed in the third semester. In this stage, the teaching of specialized English should be strengthened to cultivate students' comprehensive competence of applying English by putting the students' listening, speaking and comprehensive communicative competence in the primary position of teaching, so that the students are qualified to serve the society directly.

\subsection{Reform of teaching content and teaching mode}

The flexible and diverse teaching mode is an effective means to stimulate students' learning interest and make them learn with integrated motivation. The results of the survey show that $56 \%$ of the college students are dissatisfied with the current teaching content and teaching mode. Therefore, teachers should make more efforts in the process of course designs and the optimization of English teaching. A variety of extracurricular activities should be carried out to create an environment for English learning. For example, teachers can combine the subject characteristics of English, appropriately add more practice into the course, and set up oral groups for oral communication in teaching. In extracurricular activities, teachers can communicate with students by email or in other ways to answer students' learning questions. In the course, students can also organize themselves to discuss the topics in the centered position. The use of various teaching methods can improve the students' interest in English learning, their enthusiasm to participate in the classroom learning and the autonomy of learning after class. 


\subsection{Optimize teaching facilities, capitalize on multimedia means and improve the effectiveness of classroom teaching}

We should gradually establish and improve the school multimedia English teaching system, and make full use of campus network and multimedia teaching software. Students' differences and individualized demands should be considered in the teachers' teaching and guidance in class and the students' learning outside the classroom. In order to achieve the best learning effectiveness, we should choose the right learning content and improve students' English comprehensive ability, especially listening and speaking in English.

\subsection{Strengthen the construction of "double-qualified teachers"}

Teachers should renew their teaching ideas and improve their own English level and teaching ability. The school should encourage teachers to improve their academic qualifications in their spare time, and sponsor teachers to study further and take part in academic conferences, short-term training and teaching seminars. Meanwhile, teachers should be encouraged to enrich their teaching experiences and take part in some training for the relevant vocational qualification certificate, so that they can be "double-qualified teachers".

\subsection{Strengthen the awareness of English teaching for professional service and deepen the reform of English teaching}

According to the training goal of higher education, different professions and jobs have different demands for students' English level. Therefore, students should be provided with different levels of English teaching according to their English levels and the requirement of their future jobs.

The practical ability of students' English and the implementation of specialized English teaching are the inevitable development direction of the English Teaching reform in colleges and universities. The specialized English teaching should be highlighted in the process of improving students' English level by strengthening the ability of direct English communication in the workplace and the learning of specialized English knowledge. For example, the materials such as production instructions, technical guidance, procedure operation, maintenance guide, etc. should be provided in the English course so that students can be more competent in the future jobs. Meanwhile, students should also be encouraged to take an active part in the workplace English test. This is also a formidable challenge for all English teachers.

\subsection{Establish a diversified evaluation system}

The English teaching should be evaluated in a more diversified way. The traditional written examination should be transferred to the oral examination and the comprehensive examination. Students should be encouraged to test themselves and evaluate their own learning process. More attention should be paid to make reasonable evaluation on the emotion, cognitive ability and behavior ability of their own learning process, so that students can continue to evaluate themselves in the process of self-evaluation. It is one of the basis of evaluating their autonomous ability at the end of the semester. Colleges and universities can organize the teachers to develop a series of teaching materials to adapt to the teaching of specialized English and the teaching materials should be "necessary and sufficient" to highlight the application of basic theoretical knowledge and the training of students' practical ability.

\section{Conclusion}

College English teaching is an important part of higher education. The reform of English teaching is a long way, and English teaching is an important link in the modernization construction of our country. It is an important prerequisite for our country to go to the world. In the reform of English teaching mode, we should constantly forge ahead, explore and reform boldly, start from the actual needs of students, break out a new path of English teaching reform, and push college English teaching to a new level, so as to train more qualified applied talents for the country. 


\section{References}

[1] Peng Lingyang. Problems in College English Teaching Reform and its Reform Direction [J]. Journal of Qiongzhou University, 2010(4):141-142.

[2] Zhang Yuzhen. Research on English learning strategies under the multimedia network environment [J]. Chinese Language Journal (foreign language education and teaching), 2014,09: 92-93,95.

[3] Liu Qizhi, Gan Guosheng. Strategies for College English Vocabulary Learning in Multimedia and Network environments [J]. Modern Educational Technology, 2009(02): 71-73.

[4] Feng Lixin. A study on the effectiveness of College English Autonomous Learning Strategies in Network Multimedia Environment [J]. Modern educational technology, 2013, 01: 59-63.

[5] Chen Jinjun, Zhang Weiran, and Di Hongliang. A study of App and College students' English Literacy [J]. English from overseas, 2015(01): 23-24.

[6] Zhang Jinlei. Analysis on the key factors of the Teaching Mode of "flipping classroom" [J]. China distance Education, 2013(10):59.

[7] Ho KK, Li KD, Xie YR, et al. The theoretical basis of "leading-subject” teaching mode [J]. Audio-visual Education Research, 2000(2): 3.

[8] Bai Yingcai. A probe into the Reform of College English Teaching in Art Colleges and Universities under the background of Mousing course [J]. Journal of Kaifeng Institute of Education, 2015(9):41-42.

[9] Chen Bingbing. MOOCS Curriculum Model: contribution and Dilemma [J]. Foreign language Audio-Visual Teaching, 2014(3): 39-40.

[10]Wang Lili, Yang Fan. A study on the Reform and Development of College English Teaching under the background of the Internet [J]. Heilongjiang higher Education Research, 2015(8): 159-162. 